\title{
The Impact of Perceived Organizational Politics and Workplace Incivility on Emotional Exhaustion: A Study of Middle Level Employees in the Apparel Sector, Western Province, Sri Lanka
}

\section{Weragama Arachchillage Nayani Madhumali Senarathna, Subasingha Mudiyanselage Dinethi Yasodara Jayarathna\# (1)}

Department of Human Resource Management, Faculty of Commerce and Management Studies, University of Kelaniya, Kelaniya, Sri Lanka

Email: madhumalisenarathna@gmail.com, *dinethiyasodara@kln.ac.lk

How to cite this paper: Senarathna, W. A. N. M., \& Jayarathna, S. M. D. Y. (2021). The Impact of Perceived Organizational Politics and Workplace Incivility on Emotional Exhaustion: A Study of Middle Level Employees in the Apparel Sector, Western Province, Sri Lanka. Open Journal of Business and Management, 9, 2197-2207.

https://doi.org/10.4236/ojbm.2021.95117

Received: July 14, 2021

Accepted: August 30, 2021

Published: September 2, 2021

Copyright $\odot 2021$ by author(s) and Scientific Research Publishing Inc. This work is licensed under the Creative Commons Attribution International License (CC BY 4.0).

http://creativecommons.org/licenses/by/4.0/

cc) (i) Open Access

\begin{abstract}
The main purpose of this study was to investigate whether there is a significant impact of perceived organizational politics on emotional exhaustion in the apparel sector of the middle-level employees in the Apparel sector, western province, Sri Lanka. There were very few studies conducted to investigate this, and further, the study examines the mediating effect of workplace incivility on the impact of perceived organizational politics on emotional exhaustion. This is a cross-sectional descriptive research in nature. A standard questionnaire was used to collect primary data through a Google form from 115 respondents. The respondents were professionals working in the apparel sector, selected from few private sector organizations in Sri Lanka. Descriptive statistics, simple and multiple regression analysis was used to analyze the data. Findings revealed that perceived organizational politics was a reason for the emotional exhaustion of the middle-level employees in the apparel sector, and this impact increased by the mediator, workplace incivility. However, the findings revealed that the perceived organizational politics and workplace incivility highly affect the employees' emotional exhaustion (Positive impact), which will be a critical problem in the future. Organizations should use mechanisms to reduce the effect.
\end{abstract}

\section{Keywords}

Emotional Exhaustion, Perceived Organizational Politics, Workplace Incivility 


\section{Introduction}

Enormous competitiveness in the global business has generated circumstances where employees perceive emotionally exhausted and diminishing energy to execute their day-to-day activities in the workplace (Jayarathna \& Dharmadasa, 2018). With the businesses' rivalries existing, employees are emotionally exhausted on the fear of loss of a job, limited promotions, work overload, and tiredness. Today, practitioners and social observers have recognized that job burnout is a social problem globally (Maslach, Schaufeli, \& Leiter, 2001). If this is neglected, employees experience emotional and physical exhaustion.

Iqbal, Mirza, Sajid and Adeel (2018) have declared that emotional exhaustion is an investigative problem for businesses worldwide. Emotional exhaustion negatively affects the organizations and employee performance where employees have possible depressive disorder, approximately $46 \%$ and emotionally exhausted nearly $41 \%$ in the Covid 19 pandemic situation (Luceño-Moreno et al., 2020). Even in the Sri Lankan context, researcher explored the impact on emotional exhaustion (Azharudeen \& Arulrajah, 2018; Jayarathna \& Dharmadasa 2018; Thisera \& Bandara, 2017; Thisera \& Silva, 2017). Specifically, Azharudeen and Arulrajah (2018) found that $74 \%$ of Sri Lankan employees in the apparel industry are emotionally exhausted. Hence, it is evident that emotional exhaustion is a prevalent problem in the Sri Lankan context. Still, limited studies have investigated the impact of emotional exhaustion in the apparel sector in Sri Lanka, where the apparel industry is identified as a valuable part of the Sri Lankan economy and providing a significant amount of employment opportunities (Azharudeen \& Arulrajah, 2018).

Emotional exhaustion is an effect on different factors like sexualization of the work environment (Bui, Pinto, \& Srivastava, 2019), long term customer relationships development (Lee \& Huang, 2020), Machiavellian leadership (Stradovnik \& Stare, 2018), emotion regulation (reappraisal \& suppression) (Lee \& Jang, 2019), task-level job demand (Laila \& Hanif, 2017), turnover intention (Kyei-Poku, 2019; Park, 2019), work intensity and life satisfaction (Boekhorst, Singh, \& Burke 2017), workplace incivility (Alola, Avci, \& Ozturen, 2020; Karatepe, Kim, \& Lee, 2019; Tong, Chong, \& Johnson, 2019), and perceived organizational politics (Makhdoom, Mehmood, \& Atta, 2017; Naseer, Raja, \& Donia, 2016). Extant literature revealed that the effect of perceived organizational politics and workplace incivility is significant on exhaustion comparative to other predictors. Hence, the present study focuses on investigating the impact of Perceived Organizational Politics (POP) on emotional exhaustion with the mediating effect of Workplace Incivility (WI) with special reference to the apparel sector in Sri Lanka.

\section{Literature Review}

\subsection{Emotional Exhaustion (EE)}

People emotionally exhaust due to work overload, work-family conflicts, tardi- 
ness related to their education, working life, day to day activities, family relationships and other vital relationships. Emotional exhaustion is the consumption of sentimental energy required to encounter job demands (Maslach et al., 1986). Emotional exhaustion is evolved as a syndrome of job burnout. In demanding and stressful situations, emotional exhaustion acts as a component of burnout syndrome and is a psychological response to the job (Cordes \& Dougherty, 1993). Emotional exhaustion is a component of job burnout; the impact of job burnout indirectly affected emotional exhaustion.

Lee and Huang (2020) revealed that increasing work-family conflicts lead to increased emotional exhaustion. Everyone loves their families and to stay with family happily. Losing family relationships, withdrawing from the family due to time constraints or energy constraints lead to stress and exhaustion.

Bui et al. (2019) revealed that even though flexible work arrangements create a positive working environment, yet it arises sexualization at work, consequently increasing emotional exhaustion. Moreover, when individuals are emotionally exhausted, they diminished their performance with negative attitudes and feelings. On the other hand, it increases absenteeism and later tends to quit the jobs. On the same note, Azharudeen and Arulrajah (2018) suggested that one of the reasons for employees' turnover intention is emotional exhaustion. Eventually, the organization's overall productivity diminishes by the main reason emotional exhaustion creates a crucial issue around the world.

\subsection{Perceived Organizational Politics (POP)}

Organizational Politics (OP) is one of the most common and popular concepts of informal discussion for its employees (Gandz \& Murray, 1980). Perceived organizational politics expound as casual, conventional, ordinarily, schismatic and illegitimate behaviour aimed at displacing legitimate power (Khattak, Zolin, \& Muhammad, 2021). Perceived organizational politics is an attribute of all organizations without considering its nature and sizes, like small, medium, and large organizations (Varshney, 2019).

\subsection{Workplace Incivility (WI)}

Workplace incivility is rudeness, ignoring others, abuse of relationships, and deterioration of empathy (Pearson, Andersson, \& Porath, 2000), which signifies low-intensity workplace deviant behaviours. Schilpzand, Leavitt and Lim (2016) classified three aspects of workplace incivility namely; experienced incivility witnessed incivility, and instigated incivility. Experienced incivility is when incivility is learned from victims perspective, where witnessed incivility is learned from the observer's perspective. Instigated incivility is when incivility is learned from instigator's point of view (Reich \& Hershcovis, 2015).

Hur, Kim, and Park (2015) mentioned two types of incivility; coworker incivility and customer incivility. Coworker incivility is behaving in a discourteous manner with coworkers and, where customer incivility is rude behaviours in- 
stigated by customers towards employees. Enhancing both of these increases workplace incivility resulting increasing emotional exhaustion. Further previous researchers highlighted workplace incivility is highly related to employee turnover, as no employee wants to be in an organization with an uncomfortable environment.

\subsection{Perceived Organizational Politics, Workplace Incivility and Emotional Exhaustion}

Previous literature on POP and EE, highlighted that Perceived organizational politics significantly affects emotional exhaustion (Makhdoom et al., 2017; Naseer et al., 2016). Further, Makhdoom et al. (2017) clarify that job burnout is characterized by emotional exhaustion and has a positive relationship between perceived organizational politics and job burnout (included emotional exhaustion). Even so, limited research studies were conducted on this area worldwide, similarly in Sri Lanka.

Perceived organizational politics significantly affects workplace incivility (Khattak et al., 2021). Further, Arogundade, Arogundade, \& Gbabijo (2016) revealed in a study conducted in Nigeria that perceived organizational politics significantly influences workplace incivility. A study conducted by Makhdoom et al. (2017) expounded that there is a significant impact of perceived organizational politics on the workplace incivility of high school teachers at private and government schools. Furthermore, there were previous studies conducted and investigated that workplace incivility significantly affects emotional exhaustion (Alola et al., 2020; Hur et al., 2016; Karatepe et al., 2019; Peng et al., 2016; Rahim \& Cosby, 2016; Tong et al., 2019). However, there is a lack of studies on this area in the apparel sector.

Hence, with the explanations of previous studies, the current study explains that perceived organizational politics and workplace incivility work as predictors of emotional exhaustion and workplace incivility act as a mediator. However, the impact of perceived organizational politics on emotional exhaustion is not clear and consistent in extant literature. Further, mediation of workplace incivility is a novel contribution of this study; thus, the following hypotheses were developed to be tested in the present study and depicted in Figure 1.

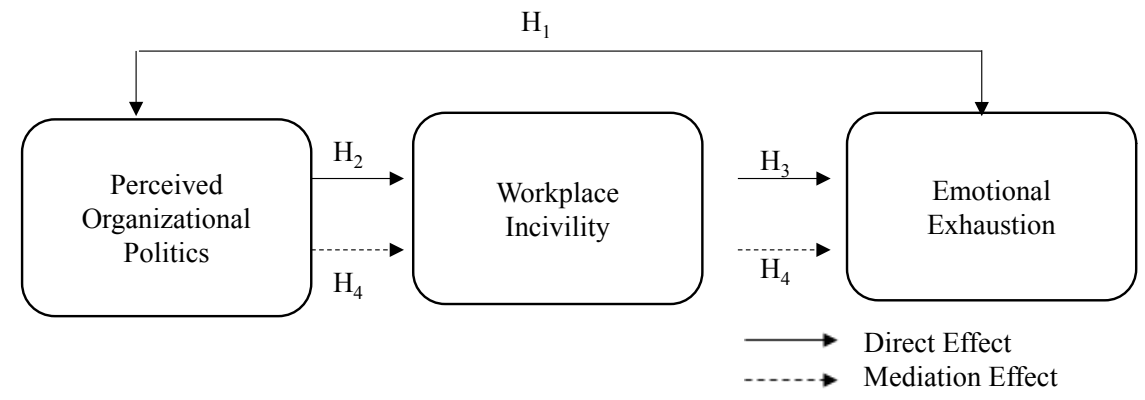

Figure 1. Conceptual model. 
$\mathrm{H}_{1}$ : There is a significant impact of perceived organizational politics on emotional exhaustion.

$\mathrm{H}_{2}$ : There is a significant impact of perceived organizational politics on workplace incivility.

$\mathrm{H}_{3}$ : There is a significant impact of workplace incivility on emotional exhaustion.

$\mathrm{H}_{4}$ : There is a mediation effect of workplace incivility on the impact of perceived organizational politics on emotional exhaustion.

\section{Method}

\subsection{Procedure and Participants}

This study took place among middle-level employees in the apparel industry in the western province in Sri Lanka. Data were collected using an online questionnaire. Total 145 questionnaires were distributed were 115 respondents responded, where the response rate is $79 \%$. All responses were used for data analyses.

Table 1 illustrates the frequency distribution of the respondents of the sample. Sixty-six respondents are male, while forty-nine respondents are female. $43 \%$ of females are middle-level employees, and most of the study sample comprises

Table 1. Respondents' profile.

\begin{tabular}{ccc}
\hline & Frequency & Percentage \\
\hline Gender & 66 & 57.4 \\
Male & 49 & 42.6 \\
Female & & \\
Age & 28 & 24.3 \\
20 - 24 Years & 45 & 39.1 \\
25 - 30 Years & 30 & 26.1 \\
31 - 35 Years & 12 & 10.4 \\
36 Above & & \\
Work experience & 17 & 14.8 \\
Less than 1 year & 22 & 19.1 \\
1 - 2 Years & 36 & 31.3 \\
2 - 3 Years & 40 & 34.8 \\
More than 3 years & & 40.9 \\
Designation & 52 & 45.2 \\
Assistant & 16 & \\
Executive & & \\
Manager & & \\
\hline
\end{tabular}

Source: Survey Data (2021) 
male middle-level employees (57\%). 39\% middle-level employees are in the age group of 25 - 30 years, and $26 \%$ are $31-35$ years of age group (26\%). Most of the respondents (40 respondents) have more than 3-year of working experience, while $19 \%$ of respondents (22) have 1 - 2 years of working experience and 36 respondents (31\%) have 2 - 3 years of working experience. However, only 17 respondents (15\%) from the total sample have working experience for less than one year.

\subsection{Measures}

\section{Emotional Exhaustion}

Emotional exhaustion measure was developed by the Maslach Burnout Inventory (Maslach, Jackson, Leiter, Schaufeli, \& Schwab, 1986) included eight items. The items were rated on a five-point Likert scale ranging from 1 "Strongly agree" to 5 "Strongly disagree". Sample items are "I feel emotionally drained from my work", "I feel used up at the end of the workday".

\section{Perceived Organizational Politics}

A six-item scale adopted from Kacmar and Carlson (1997) was used to measure the perceived organizational politics of employees. The items were rated on a five-point Likert scale ranging from 1 "Strongly agree" to 5 "Strongly disagree".

\section{Workplace Incivility}

A seven-item scale of Cortina, Magley, Williams, and Langhout (2001) was used measure workplace incivility. The items were rated on a five-point Likert scale ranging from 1 "Strongly agree" to 5 "Strongly disagree".

\section{Results}

Data were analyzed using SPSS 26.0. Basic preliminary analyses were conducted to determine the distribution of the data set, validity and reliability of the scales, along with Pearson's correlation. Hypotheses were tested using simple linear regression, and multiple linear regression.

\subsection{Descriptive Statistics and Correlations}

The normal distribution of the data set assured using skewness and kurtosis, where the statistics are lying within the cutoff values (+2 and -2$)$ (Garson, 2012). Accordingly, means range from 3.8472 to 3.9768 and the Median ranges from 4.1250 to 4.7143 . From Table 2 , it is evident that POP is strongly positively related

Table 2. Descriptive statistics and correlations.

\begin{tabular}{ccccccc}
\hline Variable & Mean & Median & Skewness & Kurtosis & EE & POP \\
\hline EE & 3.8750 & 4.1250 & -0.725 & -0.816 & & \\
POP & 3.9768 & 4.1667 & -0.782 & -0.631 & $0.894^{* *}$ & \\
WI & 3.8472 & 4.7143 & -0.682 & -1.078 & $0.936^{* *}$ & $0.883^{* *}$ \\
\hline
\end{tabular}

${ }^{*}$ Correlation is significant at the 0.01 level (2-tailed). EE-Emotional Exhaustion, POP-Perceived Organizational Politics, WI-Workplace Incivility. 
to emotional exhaustion ( $\mathrm{r}=-0.894, p<0.01)$. Further, Table 2 shows that there is a strong positive relationship between emotional exhaustion and $\mathrm{WI}(\mathrm{r}=$ $0.936, p<0.01)$, and there is a strong positive relationship between POP and WI $(\mathrm{r}=0.883, p<0.01)$.

\subsection{Validity and Reliability}

The data set's reliability and validity ensured using Cronbach's Alpha and KMO and Bartlett's test. Kaiser-Meyer-Olkin Measure of Sampling Adequacy (KMO > $0.7)$ and significance of Bartlett's Chi-Square $(p<0.05)$ exist. Thus, construct validity is justified. Item internal consistency of the measures ensured using Cronbach's Alpha $(\alpha>0.7)$ (Nunnally \& Bernstein, 1978) shown in Table 3.

\subsection{Hypotheses Testing}

Research hypotheses and the significance of the model tested using simple and multiple linear regression analysis. Table 4 shows that perceived organizational politics has $80 \%$ of positive impact on emotional exhaustion. Thus, $\mathrm{H}_{1}$ is accepted. Further, there is a positive impact (78\% positive impact) of perceived organizational politics on workplace incivility, and a positive impact ( $88 \%$ positive impact) of workplace incivility on emotional exhaustion. Thus, $\mathrm{H}_{1}, \mathrm{H}_{2}$, and $\mathrm{H}_{3}$, are accepted. Further, mediation analysis shows that the $\mathrm{R}_{2}$ value has increased with the mediation, which is significant. Thus $\mathrm{H}_{4}$ is accepted. Consequently,

Table 3. Validity and reliability analysis.

\begin{tabular}{ccccc}
\hline \multirow{2}{*}{ No of Items } & \multicolumn{2}{c}{ KMO and Bartlett's Test } & $\begin{array}{c}\text { Cronbach's } \\
\text { Alpha }(\boldsymbol{\alpha})\end{array}$ & No of Items \\
\cline { 2 - 3 } & KMO & Bartlett's Chi-Square (p-value) & No.983 & 8 \\
\hline EE & 0.939 & 799.250 & 0.919 & 6 \\
POP & 0.909 & 1496.693 & 0.986 & 7 \\
WI & 0.923 & &
\end{tabular}

EE-Emotional Exhaustion, POP_Perceived Organizational Politics, WI-Workplace Incivility.

Table 4. Simple and multiple linear regression for EE, POP, and WI.

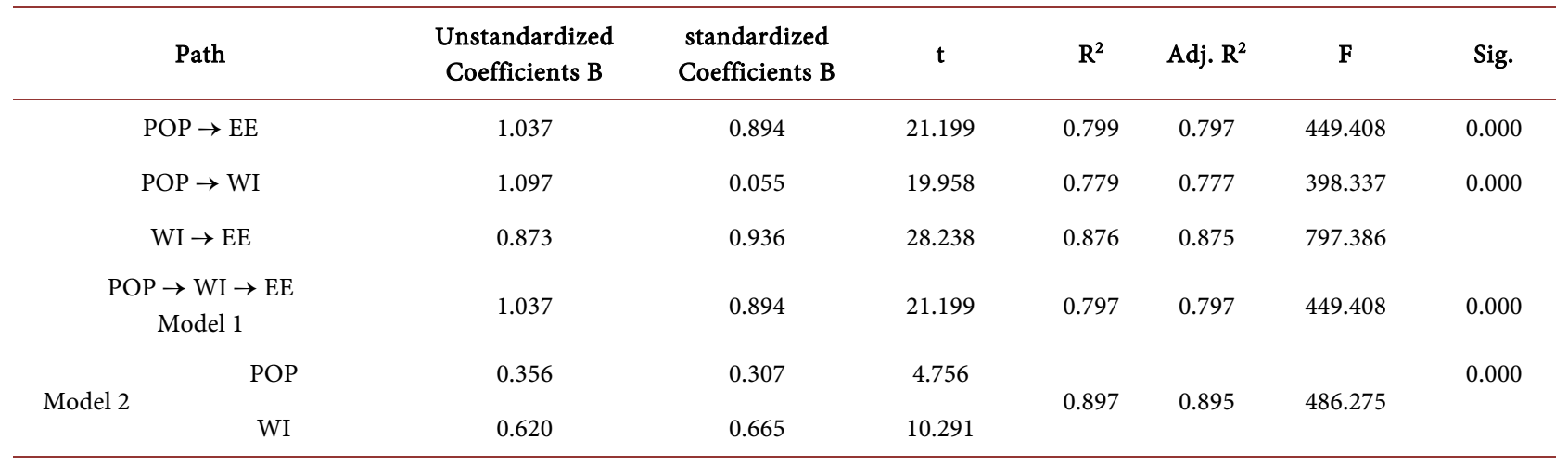

EE-Emotional Exhaustion, POP_Perceived Organizational Politics, WI-Workplace Incivility. 
workplace incivility was identified as a mediator for the impact of perceived organizational politics on emotional exhaustion.

\subsection{Discussion of Results}

This study aimed to investigate the impact of perceived organizational politics on the emotional exhaustion of middle-level employees working in the apparel industry at the western province operating in Sri Lanka. Results show that there is a significant positive impact of perceived organizational politics on emotional exhaustion and consistent with previous studies (Makhdoom et al., 2017). Perceived organizational politics significantly affects workplace incivility (Khattak et al., 2021; Makhdoom et al., 2017; Arogundade et al., 2016). However, past researchers did not explain whether it is a positive or negative impact. The current study shows that there is a positive impact of perceived organizational politics on emotional exhaustion. Moreover, Workplace incivility significantly affects emotional exhaustion (Alola et al., 2020; Hur et al., 2016; Karatepe et al., 2019; Peng et al., 2016; Rahim \& Cosby, 2016; Tong et al., 2019). The mediation adds novelty for this study as workplace incivility was a mediator of perceived organizational politics on emotional exhaustion.

\subsection{Limitations and Suggestions for Future Researchers}

Although the present study contributes to theory and practices about the impact of perceived organizational politics on emotional exhaustion with the mediating effect of workplace incivility in the apparel sector, some study limitations emerge in the current study. This study was conducted using middle-level employees in the apparel sector in the western province of Sri Lanka. It affects the generalizability of findings of the study over the population. Future researchers can enlarge the sample. The researcher shared only Google forms through Gmail or WhatsApp, or any other online platforms and has not used interviews. Future studies can mix both questionnaires and interviews and given as in depth analysis of study variables. Next, the researcher collected data at once and executed it as a cross-sectional study that may affect the causality. Future researchers can adopt a longitudinal analysis to confirm the findings further. Finally, the current study investigated the impact of POP on emotional exhaustion with the mediating effect of workplace incivility. Future researchers can develop this model by adding variables like perceived organizational support and moderators like emotional intelligence.

\section{Conclusion and Implications}

The study intended to investigate the impact of perceived organizational politics on emotional exhaustion of middle-level employees in the apparel industry in Sri Lanka. The findings reveal that perceived organizational politics is positively associated with emotional exhaustion. At the same time, the impact of perceived organizational politics on emotional exhaustion is significantly positively related 
to the mediator of workplace incivility. The findings of the current study are helpful to fill the empirical gaps in the literature on perceived organizational politics and emotional exhaustion with the mediating effect of workplace incivility. Identifying workplace incivility as a mediator is the novelty of this study. This study provides theoretical and practical knowledge with the research guide for academics and managers interested in these variables. This research opens access for further research studies in this area. It is helpful for the various professionals in the business field, especially for the private sector organizations, to recognize the importance of perceived organizational politics to diminish emotional exhaustion within the organization. Every business organization should pay more attention to managing perceived organizational politics and reducing workplace incivility and emotional exhaustion.

\section{Conflicts of Interest}

The authors declare no conflicts of interest regarding the publication of this paper.

\section{References}

Alola, U. V., Avc1, T., \& Öztüren, A. (2020). The Nexus of Workplace Incivility and Emotional Exhaustion in Hotel Industry. Journal of Public Affairs, Article No. e2236. https://doi.org/10.1002/pa.2236

Arogundade, O. T., Arogundade, A. B., \& Gbabijo, O. (2016). The Influence of Perceived Organizational Politics on Workplace Incivility among Private and Public Employees in Ogun State, Nigeria. Canadian Social Science, 12, 40-45.

Azharudeen, N. T., \& Arulrajah, A. A. (2018). The Relationships among Emotional Demand, Job Demand, Emotional Exhaustion and Turnover Intention. International Business Research, 11, 8-18. https://doi.org/10.5539/ibr.v11n11p8

Boekhorst, J. A., Singh, P., \& Burke, R. (2017). Work Intensity, Emotional Exhaustion and Life Satisfaction: The Moderating Role of Psychological Detachment. Personnel Review, 46, 891-907. https://doi.org/10.1108/PR-05-2015-0130

Bui, H. T., Pinto, J., \& Srivastava, A. (2019). Sexualization of the Work Environment and Emotional Exhaustion. International Journal of Manpower, 40, 558-573. https://doi.org/10.1108/IJM-05-2017-0106

Cordes, C. L., \& Dougherty, T. W. (1993). A Review and an Integration of Research on Job Burnout. Academy of Management Review, 18, 621-656. https://doi.org/10.5465/amr.1993.9402210153

Cortina, L. M., Magley, V. J., Williams, J. H., \& Langhout, R. D. (2001). Incivility in the Workplace: Incidence and Impact. Journal of Occupational Health Psychology, 6, 64-80.

Gandz, J., \& Murray, V. V. (1980). The Experience of Workplace Politics. Academy of Management Journal, 23, 237-251.

Garson, G. D. (2012). Testing Statistical Assumptions. Statistical Associates Publishing.

Hur, W. M., Moon, T., \& Jun, J. K. (2016). The Effect of Workplace Incivility on Service Employee Creativity: The Mediating Role of Emotional Exhaustion and Intrinsic Motivation. Journal of Services Marketing, 30, 302-315.

https://doi.org/10.1108/JSM-10-2014-0342 
Hur, W. M., Kim, B. S., \& Park, S. J. (2015). The Relationship between Coworker Incivility, Emotional Exhaustion, and Organizational Outcomes: The Mediating Role of Emotional Exhaustion. Human Factors and Ergonomics in Manufacturing \& Service Industries, 25, 701-712.

Iqbal, Z., Mirza, A. M., Sajid, M., \& Adeel, M. (2018). Impact of Emotional Labor on Emotional Exhaustion and Job Satisfaction in Public Sector Organizations. International Journal of Human Resource Studies, 8, 208-226.

https://doi.org/10.5296/ijhrs.v8i4.13936

Jayarathna, S. M. D. Y., \& Dharmadasa, P. (2018, October). Perceived Supervisor Support and Perceived Coworker Support on Emotional Exhaustion: A Study on Middle Level Employees of Multinational Companies Operating in Sri Lanka [Paper Presentation]. 2nd International Conference on Innovative Research in Science, Technology and Management (ICIRSTM-18), Singapore, 29-30 September 2018, 1.

Karatepe, O. M., Kim, T. T., \& Lee, G. (2019). Is Political Skill Really an Antidote in the Workplace Incivility-Emotional Exhaustion and Outcome Relationship in the Hotel Industry? Journal of Hospitality and Tourism Management, 40, 40-49. https://doi.org/10.1016/j.jhtm.2019.06.001

Kacmar, K. M., \& Carlson, D. S. (1997). Further Validation of the Perceptions of Politics Scale (POPS): A Multiple Sample Investigation. Journal of Management, 23, 627-658.

Khattak, M. N., Zolin, R., \& Muhammad, N. (2021). The Combined Effect of Perceived Organizational Injustice and Perceived Politics on Deviant Behaviors. International Journal of Conflict Management, 32, 62-87. https://doi.org/10.1108/IJCMA-12-2019-0220

Kyei-Poku, I. (2019). The Influence of Fair Supervision on Employees' Emotional Exhaustion and Turnover Intentions. Management Research Review, 42, 1116-1132. https://doi.org/10.1108/MRR-12-2018-0494

Laila, U., \& Hanif, R. (2017). The Impact of Task Level Demands, Work Group Level Support and Affective Commitment on Emotional Exhaustion among Services Managers: A Mediating Moderating Perspective. Humanomics, 33, 441-452. https://doi.org/10.1108/H-12-2015-0081

Lee, C. J., \& Huang, S. Y. (2020). Double-Edged Effects of Ethical Leadership in the Development of Greater China Salespeople's Emotional Exhaustion and Long-Term Customer Relationships. Chinese Management Studies, 14, 29-49. https://doi.org/10.1108/CMS-06-2018-0579

Lee, M., \& Jang, K. S. (2019). Nurses' Emotions, Emotion Regulation and Emotional Exhaustion. International Journal of Organizational Analysis, 27, 1409-1421. https://doi.org/10.1108/IJOA-06-2018-1452

Luceño-Moreno, L., Talavera-Velasco, B., García-Albuerne, Y., \& Martín-García, J. (2020). Symptoms of Posttraumatic Stress, Anxiety, Depression, Levels of Resilience and Burnout in Spanish Health Personnel during the COVID-19 Pandemic. International Journal of Environmental Research and Public Health, 17, Article No. 5514. https://doi.org/10.3390/ijerph17155514

Makhdoom, I. F., Mehmood, B., \& Atta, M. (2017). Mediating Role of Job Burnout for the Relationship of Perceived Organizational Politics and Counterproductive Work Behaviors among School Teachers. Journal of Behavioural Sciences, 27, 149-164.

Maslach, C., Jackson, S. E., Leiter, M. P., Schaufeli, W. B., \& Schwab, R. L. (1986). Maslach Burnout Inventory (Vol. 21, pp. 3463-3464). Consulting Psychologists Press.

Maslach, C., Schaufeli, W. B., \& Leiter, M. P. (2001). Job Burnout. Annual Review of 
Psychology, 52, 397-422. https://doi.org/10.1146/annurev.psych.52.1.397

Naseer, S., Raja, U., \& Donia, M. B. L. (2016). Effect of Perceived Politics and Perceived Support on Bullying and Emotional Exhaustion: The Moderating Role of Type A Personality. The Journal of Psychology, 150, 606-624.

https://doi.org/10.1080/00223980.2016.1154809

Nunnally, J. C., \& Bernstein, I. (1978). Psychometric Theory. MacGraw-Hill.

Park, R. (2019). Responses to Emotional Exhaustion: Do Worker Cooperatives Matter? Personnel Review, 48, 438-453. https://doi.org/10.1108/PR-08-2017-0253

Pearson, C. M., Andersson, L. M., \& Porath, C. L. (2000). Assessing and Attacking Workplace Incivility. Organizational Dynamics, 29, 123-137. https://doi.org/10.1016/S0090-2616(00)00019-X

Peng, Y.-C., Chen, L.-J., Chang, C.-C., \& Zhuang, W.-L. (2016) Workplace Bullying and Workplace Deviance: The Mediating Effect of Emotional Exhaustion and the Moderating Effect of Core Self-Evaluations. Employee Relations, 38, 755-769.

https://doi.org/10.1108/ER-01-2016-0014

Rahim, A., \& Cosby, D. M. (2016). A Model of Workplace Incivility, Job Burnout, Turnover Intentions, and Job Performance. Journal of Management Development, 35, 1255-1265. https://doi.org/10.1108/JMD-09-2015-0138

Reich, T. C., \& Hershcovis, M. S. (2015). Observing Workplace Incivility. Journal of Applied Psychology, 100, 203-246.

Schilpzand, P., Leavitt, K., \& Lim, S. (2016). Incivility Hates Company: Shared Incivility Attenuates Rumination, Stress, and Psychological Withdrawal by Reducing Self-Blame. Organizational Behavior and Human Decision Processes, 133, 33-44. https://doi.org/10.1016/j.obhdp.2016.02.001

Stradovnik, K., \& Stare, J. (2018). Correlation between Machiavellian Leadership and Emotional Exhaustion of Employees. Leadership \& Organization Development Journal, 39, 1037-1050. https://doi.org/10.1108/LODJ-06-2018-0232

Thisera, T. J. R., \& Bandara, W. B. M. A. P. L. (2017). The Impact of Emotional Labor on Emotional Exhaustion of Academics in State Universities of Sri Lanka. Kelaniya Journal of Human Resource Management, 12, 101-109. http://doi.org/10.4038/kjhrm.v12i1.43

Thisera, T. J. R., \& Silva, D. P. A. K. H. (2017). The Impact of Emotional Labour on Emotional Exhaustion of Female Nurses in Sri Lanka. International Conference on Management Business and Economices, Kuala Lumpur, 17-18 March 2017, 74-80.

Tong, J., Chong, S., \& Johnson, R. E. (2019). The Indirect Relations of Workplace Incivility with Emotional Exhaustion and Supportive Behaviors via Self-Blame: The Moderating Roles of Observed Incivility and Trait Emotional Control. Journal of Organizational Behavior, 40, 931-946. https://doi.org/10.1002/job.2399

Varshney, D. (2019). Relationship between Social Loafing and the Self-Concept: Mediating Role of Perceived Organizational Politics. Journal of Indian Business Research, 11, 60-74. https://doi.org/10.1108/JIBR-11-2017-0230 